\title{
Demyelinating Events Following Initiation of Anti-TNFa Therapy in the British Society for Rheumatology Biologics Registry in Rheumatoid Arthritis
}

Thomas R.P. Taylor, MBChB, James Galloway, MRCP, PhD, Rebecca Davies, MSc, Kimme Hyrich, FRCPC, PhD, and Ruth Dobson, MRCP, PhD

Neurol Neuroimmunol Neuroinflamm 2021;8:e992. doi:10.1212/NXI.0000000000000992

\section{Abstract}

\section{Objective}

To establish the incidence of demyelination in patients who have received anti-tumor necrosis factor alpha (anti-TNFa) therapy, through analysis of adverse events reported in a prospective cohort of patients receiving biological therapies.

\section{Methods}

A cohort study was performed on prospectively acquired data via the British Society for Rheumatology Biologics Register in Rheumatoid Arthritis. All potential demyelinating events during follow-up were extracted and classified as definite, probable, or possible blinded to treatment data. The point of starting an anti-TNF therapy in individuals with no prior reported demyelination was the time of exposure. Crude rates of demyelination and standardized incident rates (SIRs) compared with the general UK population were calculated.

\section{Results}

Thirty-five individuals with demyelinating events were identified from a total pool of 13,489 . The median age at study entry was 44 years, and the median disease duration was 8 years; $71 \%$ were female. Events occurred a median of 3 (interquartile range 1-5) years from the start of the first anti-TNF therapy. Twenty-six events occurred in individuals still taking anti-TNF $\alpha$ therapy; of the other 9, 6 were within 90 days of drug withdrawal. The raw incidence of demyelination was 19.7/100,000 patient-years (95\% CI 13.7-27.3). The SIR in the whole population was 1.38 (95\% CI $0.96-1.92)$ and $0.83(0.51-1.26)$ limited to definite/probable cases.

\section{Conclusions}

Demyelination following anti-TNF therapy is uncommon. Patients receiving anti-TNFa therapy show a marginally increased SIR; this is lost in sensitivity analyses. Patients concerned about anti-TNF $\alpha$-associated demyelination can be relatively reassured by these data.

\author{
Correspondence \\ Dr. Dobson \\ ruth.dobson@qmul.ac.uk
}




\section{Glossary}

csDMARD = conventional synthetic disease-modifying antirheumatic drug; $I Q R=$ interquartile range; $M S$ = multiple sclerosis; pyears = person-years; $\mathbf{R A}=$ rheumatoid arthritis; SIR = standardized incident rate; $\mathbf{T N F} \mathfrak{\alpha}=$ tumor necrosis factor alpha.

Anti-tumor necrosis factor alpha (anti-TNF $\alpha)$ monoclonal antibodies are used to treat a number of autoimmune diseases, including rheumatoid arthritis (RA), psoriasis, inflammatory bowel disease, and uveitis. Approved anti-TNFa therapies include etanercept (a decoy TNF receptor protein) and adalimumab, infliximab, certolizumab, and golimumab (monoclonal antibodies directed against TNF $\alpha$ ). As a class, anti-TNF $\alpha$ therapies have been associated with de novo CNS demyelination. ${ }^{1}$ A clinical trial of lenercept, a recombinant TNF receptor p55 immunoglobulin fusion protein with a biological action of TNF- $\alpha$ blockade in multiple sclerosis (MS), failed to reach its primary MRI-based end point. ${ }^{2}$ Concerningly, an increased relapse rate was seen early in the lenercept group with more severe neurologic deficits in the lenercept-treated group compared with placebo. ${ }^{2}$

The pathophysiologic relationship between tumor necrosis factor and MS is complex. rs1800693, a single nucleotide polymorphism in the TNFRSF1A gene, which encodes tumor necrosis factor receptor 1 , has been implicated as a causal variant in the development of MS. ${ }^{3}$ The MS risk allele appears to lead to the expression of a soluble form of tumor necrosis factor receptor 1, which blocks TNF. It has been hypothesized that anti-TNF $\alpha$ therapies have an impact on MS risk via this mechanism; however, direct evidence supporting this hypothesis is lacking.

Despite the lack of direct evidence, there remain significant concerns around the use of anti-TNFa therapies in some patients. Some patients in whom anti-TNF $\alpha$ therapy is being considered may be referred to neurologists for assessment of the risk of demyelination, particularly those with neurologic symptoms or a family history of MS. Evaluating this risk is highly complex, with little data to inform risk-benefit discussions. Performing screening MRI on all patients considering anti-TNF $\alpha$ therapy is not feasible from a resource perspective, and the use of MRI in this way confers a risk of significant anxiety in patients as a result of incidental diagnoses with varying degrees of clinical significance being revealed. ${ }^{4}$

The British Society for Rheumatology Biologics Register in Rheumatoid Arthritis (BSRBR-RA) is a large, prospective pharmacovigilance study that aims to monitor the safety of anti-TNF $\alpha$ in patients with RA and related conditions. ${ }^{5}$ To date, more than 20,000 patients started on biologic therapy have been enrolled in the register. It thus provides a prospectively collected resource, enabling the study of rare adverse events occurring on or subsequent to anti-TNF $\alpha$ therapy. We set out to describe the characteristics and incidence of demyelination in patients who have received anti-
$\mathrm{TNF} \alpha$ therapy to better inform both patients and clinicians and enable evidence-based decision making.

\section{Methods}

\section{Case Identification}

The study population comprised patients recruited to the BSRBR-RA, a prospective observational cohort study, up to November 30, 2019. Full methods have previously been described in detail. ${ }^{6}$ Briefly, baseline data (with baseline defined as at the time of starting a biological agent) are recorded by the treating rheumatologist or clinical research nurse using a standardized questionnaire. Data collected include demographics (age and sex), rheumatologic disease status (disease duration, joint counts, disease activity score $28,{ }^{7}$ Health Assessment Questionnaire), ${ }^{8}$ disease indication, drug history, and comorbidities. Any prior history of demyelination at study registration is also recorded. Follow-up data are collected 6-monthly for the first 3 years following enrollment and annually thereafter, regardless of subsequent treatment changes. Follow-up data include current treatments, changes to antirheumatic therapy, and occurrence of serious and nonserious adverse events, including demyelination. All adverse events are reported verbatim by clinicians and coded centrally using the Medical Dictionary for Regulatory Activities. ${ }^{9}$ The BSRBR-RA is also linked to the mandatory national death register and is informed of any death and cause of death in patients registered in the study.

To be eligible for the current study, patients were required to have baseline registration with the BSRBR-RA at the time of starting an anti-TNFa therapy, have at least one 6-monthly follow-up recorded after registration, and have no known history of demyelination before registration. Patients entered into the BSRBR-RA with primary diagnoses other than RA, such as psoriatic arthritis, were included. All individual subject-level records meeting the above criteria were searched using both the Medical Dictionary for Regulatory Activities preferred terms and free-text event descriptions related to demyelination (search terms given in table e-1, links.lww. com/NXI/A467). All records identified using these search terms were retrieved, and the available clinical records reviewed.

Cases of incident demyelination were defined as any reported adverse event of demyelination in patients with no previous history of demyelination recorded at baseline. Demyelinating events affecting the CNS were categorized using available clinical information, blinded to underlying rheumatologic 
diagnosis, anti-TNFa therapy subtype, and start/stop date, by a consultant neurologist specializing in neuroinflammation/ MS (R.D.). Demyelinating events of interest were defined as those involving the CNS, including the spinal cord and optic nerve. Peripheral demyelinating events, such as chronic inflammatory demyelinating polyneuropathy, CIDP, and Guillain-Barre syndrome/acute inflammatory demyelinating polyneuropathy, AIDP, were excluded. Where available, brain and spine MRI reports and the results of neurophysiologic investigations were included in the review of clinical information, although the absence of data was not assumed to mean investigations were normal. Events were classified as definite MS, definite demyelination (but not meeting diagnostic criteria for MS), probable demyelination, and possible demyelination based on a framework informed by MacDonald 2017 criteria. $^{10}$

\section{Statistical Methods}

For all patients, person-years (pyears) of exposure started from the date of the first treatment with the respective drug and continued until the first demyelinating event, most recent study follow-up (recorded up to November 30, 2019), or death, whichever came first. Events were only included if they occurred subsequent to anti-TNFa therapy initiation but events after the last dose of anti-TNFa, including those on subsequent therapies, were also included.

Characteristics of those patients who went on to develop a demyelinating event were described. Crude rates of demyelinating events are presented per 1,000 pyears with $95 \%$ CIs. Standardized incidence rates (SIRs) of events per 100,000 population compared with English population data based on Hospital Episode Statistics and General Practice Research Datalink data from 1997 to 2010 are also included. ${ }^{11}$ As no population data were available after 2010, the same data from 2010 were used for subsequent years. A sensitivity analysis to determine SIRs only including events classified as probable or definite demyelination was performed, and exploratory analysis included only the population with RA.

All analyses were performed using Stata, version 14 (StataCorp. 2015. Stata Statistical Software: Release 14. College Station, TX: StataCorp LP).

\section{Data Availability}

This study analyzed existing data owned by and subject to license restrictions by the British Society for Rheumatology. Data sets are available through application to the BSR. All proposals for access are assessed by the steering committee. To access data, please email bsrbr@rheumatology.org.uk.

\section{Standard Protocol Approvals, Registrations, and Patient Consents}

The BSRBR-RA holds ethical approval from the Multicentre Research Ethics Committee for the North West of England (ref MREC 00/8/053). Written informed consent is obtained from all patients.

\section{Results}

\section{Population Characteristics}

Thirty-five individuals with demyelinating events were identified from a total eligible study population of 13,489 individuals with 172,107 pyears of follow-up data available. The baseline characteristics and characteristics at the time of the initial report of demyelinating event of these 35 individuals are detailed in tables 1 and 2 .

Seventy-one percent of patients who developed demyelination had a baseline diagnosis of RA, 14\% ankylosing spondylitis, and 5\% psoriatic arthritis (table 1). The median age at BSRBR-RA registration was 44 years (interquartile range [IQR] 37-57 years), and the median age at demyelinating event was 50 years (IQR 43-59 years); $71 \%$ were female. The median disease duration at demyelinating event was 12 years (IQR 8-20 years). Patients were taking etanercept (34\%), infliximab (29\%), adalimumab (29\%), or certolizumab $(8 \%)$ at study entry. At least 1 additional comorbidity was reported in $62 \%$ of patients with recorded incident demyelination. Cardiovascular events (20\%), asthma (17\%), and depression (17\%) were the most common comorbidities reported overall. In males, asthma (20\%), liver disease $(20 \%)$, and depression (20\%) were most commonly reported; cardiovascular disease (24\%), asthma (16\%), and depression (16\%) were the most common in females (table e-2, links.lww.com/NXI/A467).

Demyelinating events occurred a median of 3 years (IQR $1-5$, range $0.2-12.1$ years) from anti-TNFa initiation. Of the individuals who had demyelinating events, 13 (37\%) occurred within 2 years and 24 (69\%) within 5 years. Twenty-six of 35 events $(74 \%)$ were reported in individuals taking anti-TNFa therapy at the time of event report. Of the 9 events that occurred in individuals not on therapy, 6 (67\%) occurred within 90 days of stopping therapy, and 3 of 35 events (9\%) had no recent exposure to anti-TNFa therapy. Nelson-Aalen cumulative hazard estimate plots indicated a steady event rate both in those with events occurring on treatment and those who had stopped treatment before event report (table 2 and figure).

The crude rate of incident demyelinating events was 19.7 per 100,000 person-years (95\% CI 13.7-27.3). The crude rate in males was 22.1 per 100,000 (95\% CI 10.6-40.7) and in females 18.8 per 100,000 (95\% CI $12.2-27.8$ ).

The SIR (age and sex corrected with Ref. 11 as the reference population) was 1.38 (95\% CI 0.96-1.92) compared with the UK Hospital Episode Statistics/General Practice Research Datalink population (total population $24,052,635)^{11}$ (table 3 ). The SIR was not significantly increased in females (SIR 1.15 , 95\% CI 0.74-1.69) but was raised in males (SIR 2.75, 95\% 1.32-5.06) (table 3). Interaction testing was not performed on the SIR due to this being based on population structure. 
Table 1 Characteristics of Patients With Incident Demyelinating Events

\begin{tabular}{|c|c|c|c|}
\hline & Total & Male & Female \\
\hline $\mathbf{N}$ & 35 & 10 & 25 \\
\hline \multicolumn{4}{|l|}{ At register entry } \\
\hline Age, median (IQR) & $44(37-57)$ & $45(34-53)$ & $44(39-60)$ \\
\hline Sex, n (\%) female & $25(71 \%)$ & - & - \\
\hline Disease duration, median (IQR) & $8(4-16)$ & $5(1-8)$ & $9(6-21)$ \\
\hline Tender joint count, median (IQR) & $8(3-16)$ & $8(2-17)$ & $8(3-14)$ \\
\hline Swollen joint count, median (IQR) & $7(3-13)$ & $4(2-11)$ & $9(5-14)$ \\
\hline ESR, median (IQR) & $26(17-79)$ & $25(19-87)$ & $28(16-74)$ \\
\hline CRP, median (IQR) & $32(11-99)$ & $32(6-148)$ & $38(16-79)$ \\
\hline DAS28 score, median (IQR) & $5.9(5.3-6.8)$ & $6.0(4.1-6.8)$ & $5.9(5.5-6.9)$ \\
\hline \multicolumn{4}{|l|}{ Indication, $\mathbf{n}(\%)$} \\
\hline Rheumatoid arthritis, RA & $25(71 \%)$ & $6(60 \%)$ & $19(76 \%)$ \\
\hline Ankylosing spondylitis, AS & $5(14 \%)$ & $2(20 \%)$ & $3(12 \%)$ \\
\hline Psoriatic arthritis, PSA & $2(5 \%)$ & $1(10 \%)$ & $1(4 \%)$ \\
\hline Other & $3(9 \%)$ & $1(10 \%)$ & $2(8 \%)$ \\
\hline Baseline steroids, $\mathbf{n}(\%)$ yes & $18(51 \%)$ & $6(60 \%)$ & $12(48 \%)$ \\
\hline \multicolumn{4}{|l|}{ Biologic at registration, $\mathbf{n}(\%)$} \\
\hline Etanercept & $12(34 \%)$ & $4(40 \%)$ & $8(32 \%)$ \\
\hline Infliximab & $10(29 \%)$ & $1(10 \%)$ & $9(36 \%)$ \\
\hline Adalimumab & $10(29 \%)$ & $3(30 \%)$ & $7(28 \%)$ \\
\hline Certolizumab & $3(8 \%)$ & $2(20 \%)$ & $1(4 \%)$ \\
\hline \multicolumn{4}{|l|}{ Comorbidities, n (\%) } \\
\hline 0 & $14(38 \%)$ & $3(30 \%)$ & $11(44 \%)$ \\
\hline 1 & $9(23 \%)$ & $4(40 \%)$ & $5(20 \%)$ \\
\hline 2 & $10(33 \%)$ & $4(40 \%)$ & $7(28 \%)$ \\
\hline $3+$ & $2(6 \%)$ & 0 & $2(8 \%)$ \\
\hline \multicolumn{4}{|l|}{ Smoking status, n (\%) } \\
\hline Current smoker & $7(21 \%)$ & $4(40 \%)$ & $3(13 \%)$ \\
\hline Former smoker & $13(38 \%)$ & $2(20 \%)$ & $11(45 \%$ \\
\hline Never smoked & $14(41 \%)$ & $4(40 \%)$ & $10(42 \%)$ \\
\hline \multicolumn{4}{|l|}{ At time of event } \\
\hline Age, median (IQR) & $50(43-59)$ & $48(35-59)$ & $50(45-60)$ \\
\hline Disease duration, median (IQR) & $12(8-20)$ & $9(4-11)$ & $15(10-24)$ \\
\hline DAS28 score, median (IQR) & $4.1(2.8-5.0)$ & $4.2(2.5-4.9)$ & $3.4(3.0-5.1)$ \\
\hline \multicolumn{4}{|l|}{ Biologic at event, $\mathrm{n}(\%)$} \\
\hline Etanercept & $6(17 \%)$ & $2(20 \%)$ & $4(16 \%)$ \\
\hline Infliximab & $1(3 \%)$ & 0 & $1(4 \%)$ \\
\hline Adalimumab & $11(31 \%)$ & $4(40 \%)$ & $7(28 \%)$ \\
\hline
\end{tabular}


Table 1 Characteristics of Patients With Incident Demyelinating Events (continued)

\begin{tabular}{llll}
\hline & Total & Male & Female \\
\hline Certolizumab & $3(8 \%)$ & $1(10 \%)$ & $2(8 \%)$ \\
\hline Rituximab & $4(12 \%)$ & $1(10 \%)$ & $3(12 \%)$ \\
\hline Anakinra & $1(3 \%)$ & 0 & $1(4 \%)$ \\
\hline Off biologic & $9(26 \%)$ & $2(40 \%)$ & $7(28 \%)$ \\
\hline Years from the start of the first anti-TNF to event & & $3(2-5)$ \\
\hline Median (IQR) & $3(1-5)$ & $1.3,9.0$ \\
\hline Range (min, max) & $0.2,12.1$ & $4(40 \%)$ \\
\hline Occurred within $\mathbf{y}, \mathbf{n}(\%)$ & $13(37 \%)$ & $3(1-5)$ \\
\hline Occurred within $\mathbf{5} \mathbf{y}, \mathbf{n}(\%)$ & $24(69 \%)$ & $6(60 \%)$ \\
\hline
\end{tabular}

Abbreviations: IQR = interquartile range; RA = rheumatoid arthritis; TNF = tumor necrosis factor.

Sensitivity analyses provided a similar estimate, excluding those with possible demyelination and including only those with definite/probable demyelination gave an overall SIR of 0.83 (95\% CI 0.51-1.26); 0.69 (95\% CI 0.39-1.14) in females and 1.65 (95\% CI 0.61-3.59) in males (table e-3a, links.lww. com/NXI/A467). Restricting the population to only those with RA (i.e., excluding those with other rheumatologic diagnoses) gave similar results - the overall SIR was 1.10 (95\% CI 0.71-1.63); sex-disaggregated rates were 0.95 (95\% CI $0.57-1.49)$ in females and 2.21 (0.81-4.80) in males (table e-3b, links.lww.com/NXI/A467). Because of the small numbers of patients with diagnoses other than RA (ankylosing spondylitis: $\mathrm{n}=5$ and psoriatic arthritis: $\mathrm{n}=2$ ), it was not appropriate to calculate the SIR for demyelination in either of these diagnoses.

Across the cohort, there was a variable amount of clinical data available. From the data available, 11 cases were judged to have an initial presentation of possible or definite MS; however, in those with insufficient data available to positively diagnose MS, this could not be excluded. There were insufficient data available for the majority of cases to identify MS subtype. Cases that did not meet the criteria for MS would all meet the criteria for clinically isolated syndrome. No cases had data available suggesting a diagnosis of neuromyelitis optica spectrum disorder, but cases could have been missed due to insufficient data. There were 12 reported cases of optic neuritis, some of whom met the diagnostic criteria for MS. Similarly, 10 reports indicated transverse myelitis, again some as presenting symptom of MS. A number of cases had MRI reports available, but not all cases, and although MRI findings were taken into account when reviewing the data, given the inconsistency in data availability, the findings are not reported. Data regarding treatment for demyelinating events were not routinely available and so were not analyzed.

\section{Discussion}

Our data support there being no substantial effect on the risk of incident demyelination associated with anti-TNF $\alpha$ therapy in a large, registry-based cohort. Although the SIR is marginally increased when looking at all incident demyelinating events, the CI crosses one, and this small effect is lost in both

Table 2 Time to Event From the Start of Anti-Tumor Necrosis Factor Alpha Therapy According to Event Occurring on or off Biologic Agent

\begin{tabular}{lll}
\hline & $\begin{array}{l}\text { Demyelinating events occurring } \\
\text { on biologic agent }(\mathbf{n}=\mathbf{2 6})\end{array}$ & $\begin{array}{l}\text { Demyelinating events occurring } \\
\text { off biologic agent }(\mathbf{n}=\mathbf{9})\end{array}$ \\
\hline Time from drug start to event (median, IQR, range) & 3.2 y (IQR 1.3-5.4; range 0.2-12 y) & 3.3 y (IQR 1.1-4.9; range 0.9-8 y) \\
\hline Occurred within $\mathbf{2} \mathbf{y}, \mathbf{n}(\%)$ & $9(35 \%)$ & $4(44 \%)$ \\
\hline Occurred within $\mathbf{5} \mathbf{y}, \mathbf{n}(\%)$ & $18(69 \%)$ & $6(67 \%)$ \\
\hline Median time since last biologic (median, IQR, range) & - & 3 mo (IQR 2-11; range 1-48 mo) \\
\hline Occurred within $\mathbf{9 0} \mathbf{d}$ of therapy cessation, $\mathbf{n}(\%)$ & - & $6(67 \%)$ \\
\hline
\end{tabular}

Abbreviation: IQR = interquartile range. 
Figure Nelson-Aalen Cumulative Hazard Estimate Plots
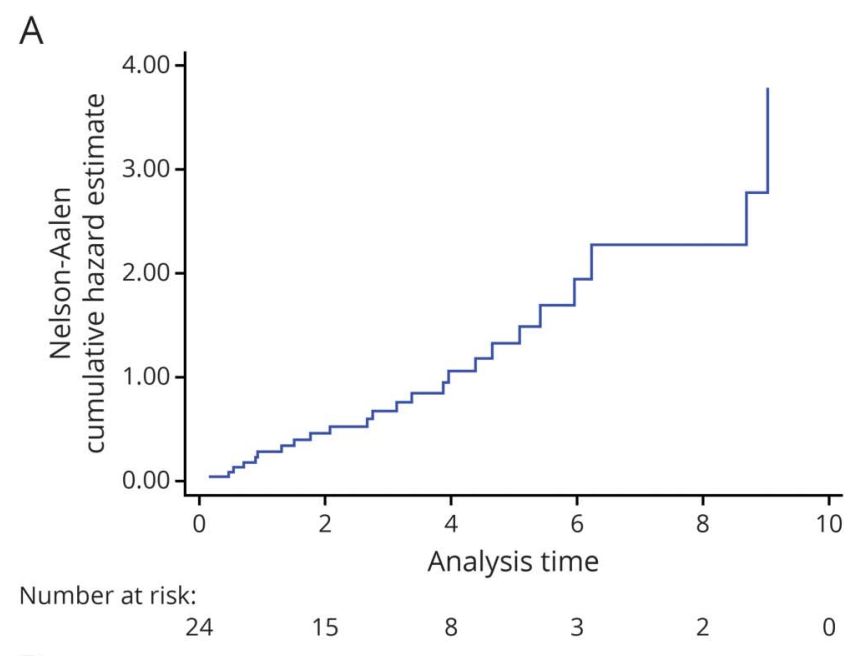

B

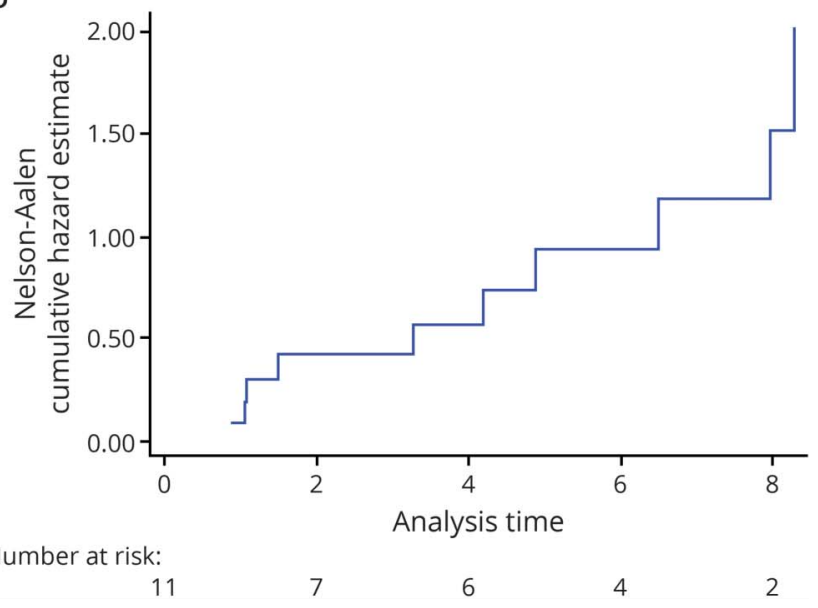

(A) Nelson-Aalen cumulative hazard estimate plot showing time to event from start of drug in patients still on biologics. (B) Nelson-Aalen cumulative hazard estimate plot showing time to event from start of drug in patients off biologics.

of the sensitivity analyses. Furthermore, the crude incidence is similar when disaggregated by sex. This finding of a lack of a marked effect is in keeping with recent data originating from Scandinavian registries. ${ }^{12}$ This result is in contrast to a recent case-control study from the United States ${ }^{13}$; however, differences in study design and statistical analysis prevent direct comparison. The BIOGEAS registry study reported a lower crude incidence ( 0.33 cases per 1,000 patients) than reported here ${ }^{14}$; however, the significant heterogeneity between studies prevents direct comparison. Of note, the BIOGEAS report does not list the cohort characteristics of included patients, further limiting comparison.

We are able to significantly extend previously published work by providing a rigorous review of included cases, with timebased survival analysis and a clear demographic and diseasespecific picture of those with CNS demyelinating events. Particular strengths of this study include the registry-type design with prospective acquisition of both treatment and events, along with the clinical data that is captured on each individual. Demyelination is an adverse event of interest in the BSRBR-RA, meaning that clinicians are alerted to report such events-as such most events in those reporting follow-up data are likely to have been captured.

It must be noted that we could not undertake a comparative analysis with patients with similar disease characteristics receiving conventional synthetic disease-modifying antirheumatic drugs (csDMARDs; such as methotrexate and sulfasalazine) on this occasion. The BSRBR-RA does follow a relatively small cohort $(n=3,700)$ of patients receiving csDMARDs, but this cohort is limited to patients with RA. At the time of data extraction for our study, there were no reports of new/incident demyelinating disease in the group receiving csDMARDs.

With a median age of 44 years at BSRBR-RA entry and 50 years at the time of event, this population has an older age at incident demyelinating event than the UK MS population, who have a median age at onset of 37 years. ${ }^{11}$ The crude incidence rate of $19.7 / 100,000$ patient-years appears to be potentially double that seen in the background UK population $(\mathrm{c} 10 / 100,000 \mathrm{pt} \text { years })^{15}$; however, given differences in population structure, these raw rates should not be directly compared.

Of interest, the crude rate reported in our study is about $50 \%$ of that reported in Scandinavian registries. ${ }^{12}$ It must be noted that both the case definition and rigorous review of included cases prevent direct comparison between the 2 , as we excluded peripheral demyelinating events, as their underlying etiology and causation pathways are thought to be different. ${ }^{16}$ The Scandinavian study including all central and peripheral demyelinating events recorded in medical registries, and thus, they would be expected to report a higher event incidence. CNS demyelinating events appear to occur at a consistent rate within our population, and there does not appear to be a marked change with cessation of therapy. However, it must be noted that there were only 3 events occurring $>3$ months following therapy cessation, which limits the conclusions that can be drawn from this.

The increased SIR that appears to be present in males is of interest. Conclusions regarding this are limited due to the small sample size and the fact that the CIs around the crude rates substantially overlap. However, a similar signal of increased risk in males is seen in the Danish cohort, but not the Swedish. ${ }^{12}$ This sex-specific signal is lost in both of the sensitivity analyses. Of interest, in this cohort, males were more likely to smoke than females; smoking is associated with an OR of MS of $1.54,{ }^{17}$ and so one potential hypothesis is that nonpharmacologic factors may be contributing to this observation.

A potential confounder is the increased risk of MS in individuals with autoimmune disease. However, a previous meta- 
Table 3 SIR Compared With English Population Data

(General Practice Research Datalink and Hospital Episode Statistics) From 1997 to $2010^{11}$

\begin{tabular}{llll}
\hline & \multicolumn{2}{l}{ Biologic cohort } & \\
\cline { 2 - 4 } & Observed & Expected & SIR $(95 \% \mathrm{CI})$ \\
\hline Female & 25 & 21.78 & $1.15(0.74-1.69)$ \\
\hline Male & 10 & 3.63 & $2.75(1.32-5.06)$ \\
\hline Total & 35 & 25.41 & $1.38(0.96-1.92)$ \\
\hline
\end{tabular}

Abbreviation: SIR = standardized incident rate.

"SIR" for demyelination events per 100,000 population.

analysis did not demonstrate an association between MS and RA (OR 1.15, 95\% CI 0.77-1.73, $p=0.49$ ), whereas a small but significant increase in the odds of comorbid psoriasis was seen in MS (OR 1.31, 95\% CI 1.09-1.57, $p<0.0001$ ). ${ }^{18}$ However, this small effect size would not be sufficient to show a signal in our cohort, particularly given the low number of individuals with psoriatic arthritis. It is more likely that where an increased SIR is seen, this is related to the fact that demyelination is an adverse event of interest in the BSRBR-RA, compared with population-based registries using GP data, and that this cohort of patients have increased health care contacts compared with the overall UK population at risk of MS.

This study is not without limitations. The BSRBR-RA is a realworld registry study: it records events, but clinicians remain responsible for treatment decisions and patients are under routine medical care. Given the well-documented concerns regarding the use of anti-TNF $\alpha$ therapies in those at risk of demyelination, they are likely to have been avoided in the highest risk cohort, such as those with a significant family history. The study cohort cannot therefore be assumed to have the same baseline risk of demyelination as the background population. Clinically reported events often had incomplete data, meaning that events may have been incorrectly assigned as possible rather than probable or definite, and this may partially explain the difference in results compared with the study from the United States, which had greater access to complete patient records. ${ }^{13}$

We did not have access to the source medical notes for individuals in whom demyelination was reported, meaning that ancillary and/or follow-up investigations were often not available. It is likely that at least some of those with events reported off therapy had demyelinating events that precipitated therapy withdrawal; however, given the similar and steady rate of decay seen in both groups, this is unlikely to have impacted on the results or their interpretation. The range of clinical phenotypes reported in the clinical data available suggests that there is no typical demyelinating presentation; however, given the limited and variable amount of data available, conclusions regarding clinical phenotypes must be guarded.
In conclusion, therefore, we find no convincing evidence of a strong impact of anti-TNFa therapy on risk of incident demyelination. Where demyelinating events are seen, there was no particular predilection for any particular CNS location or patient group. In addition, the signal of a possible small increased risk compared with the general population is lost in both of the sensitivity analyses. The small number of events (35) seen in a case population of $>13,000$ may be reassuring to both patients and clinicians considering the use of these therapies. However, given the serious nature of this potential outcome, careful consideration should still be given to their use and monitoring, particularly in those individuals at highest risk of demyelinating events.

\section{Acknowledgment}

The authors acknowledge the enthusiastic collaboration of all Consultant Rheumatologists and their Clinical Nurse Specialists across the United Kingdom in providing the data (visit bsrbr.org for a full list of contributors). The authors gratefully acknowledge the support of the National Institute for Health Research through the Comprehensive Local Research Networks at participating centers. In addition, the authors acknowledge support from the British Society for Rheumatology (BSR) Executive, the members of the BSRBR Registers Committee, and the BSRBR Project Team in London for their active role in enabling the register to undertake its tasks. The authors acknowledge the Arthritis Research UK Centre for Epidemiology (Arthritis Research UK grant no. 20380), who provided the infrastructure support for the study. This work was also supported by the NIHR Manchester Biomedical Research Centre.

\section{Study Funding}

This work was supported by the BSR. The BSR commissioned the BSRBR-RA as a UK-wide national project to investigate the safety of biologic and other targeted therapies in routine medical practice. $\mathrm{KH}$ is the chief investigator. The BSR currently receives restricted income from UK pharmaceutical companies, including AbbVie, Celltrion, Eli Lilly, Pfizer, Roche, Samsung Bioepis, Sandoz, Sanofi, and UCB, and in the past Hospira, MSD, and SOBI. This income finances a wholly separate contract between the BSR and the University of Manchester. The chief investigator and the BSRBR-RA team at the University of Manchester have full academic freedom and are able to work independently of pharmaceutical industry influence. All decisions concerning analyses, interpretation, and publication are made autonomously of any industrial contribution. Members of the BSRBR-RA University of Manchester team, BSR trustees, committee members, and staff complete an annual declaration in relation to conflicts of interest.

\section{Disclosure}

T.R.P. Taylor has no relevant conflicts to declare. J. Galloway has received speaker honoraria from AbbVie, BMS, Celgene, 
Chugai, Gilead, Janssen, Lilly, Pfizer, Novartis, and UCB. R Davies has no relevant conflicts to declare. K. Hyrich reports nonpersonal grant income from Pfizer and BMS and nonpersonal honoraria from AbbVie. R. Dobson has no conflicts of interest with direct relevance to this work. She has received grant income from Biogen, Merck, and Celgene and honoraria/support for educational activities from Merck, Biogen, Teva, Roche, and Sanofi Genzyme. Go to Neurology. org/NN for full disclosures.

\section{Publication History}

Received by Neurology: Neuroimmunology \& Neuroinflammation January 5, 2021. Accepted in final form February 22, 2021.

Appendix Authors

\begin{tabular}{|c|c|c|}
\hline Name & Location & Contribution \\
\hline $\begin{array}{l}\text { Thomas R. } \\
\text { P. Taylor, } \\
\text { MBChB }\end{array}$ & $\begin{array}{l}\text { Preventive Neurology Unit, } \\
\text { Wolfson Institute of Preventive } \\
\text { Medicine, Queen Mary } \\
\text { University of London, London, } \\
\text { Uinted Kingdom }\end{array}$ & $\begin{array}{l}\text { Drafting/revision of the } \\
\text { manuscript for content, } \\
\text { including medical } \\
\text { writing for content; } \\
\text { major role in the } \\
\text { acquisition of data; } \\
\text { study concept or } \\
\text { design; and analysis } \\
\text { or interpretation of } \\
\text { data }\end{array}$ \\
\hline $\begin{array}{l}\text { James } \\
\text { Galloway, } \\
\text { MRCP, PhD }\end{array}$ & $\begin{array}{l}\text { Centre for Rheumatic } \\
\text { Diseases, King's College } \\
\text { London, Uinted Kingdom }\end{array}$ & $\begin{array}{l}\text { Drafting/revision of the } \\
\text { manuscript for content, } \\
\text { including medical } \\
\text { writing for content; } \\
\text { study concept or } \\
\text { design; and analysis } \\
\text { or interpretation of } \\
\text { data }\end{array}$ \\
\hline
\end{tabular}

\begin{tabular}{lll}
\hline $\begin{array}{l}\text { Rebecca } \\
\text { Davies, } \\
\text { MSc }\end{array}$ & $\begin{array}{l}\text { Centre for Epidemiology } \\
\text { Versus Arthritis, The University } \\
\text { of Manchester, Manchester } \\
\text { Academic Health Science } \\
\text { Centre, Manchester, United } \\
\text { Kingdom }\end{array}$ & $\begin{array}{l}\text { Drafting/revision of the } \\
\text { manuscript for content, } \\
\text { including medical } \\
\text { writing for content, and } \\
\text { analysis or } \\
\text { interpretation of data }\end{array}$ \\
\hline $\begin{array}{l}\text { Kimme } \\
\text { Hyrich, }\end{array}$ & $\begin{array}{l}\text { Centre for Epidemiology } \\
\text { FRCPC, PhD } \\
\text { of Manchester, Manchester }\end{array}$ & $\begin{array}{l}\text { Drafting/revision of the } \\
\text { manuscript for content, } \\
\text { including medical } \\
\text { Academic Health Science } \\
\text { Centre, Manchester, United } \\
\text { Kingdom; National Institute of } \\
\text { Health Research Manchester } \\
\text { Biomedical Research Centre, } \\
\text { Manchester University NHS } \\
\text { acquisition of data; study } \\
\text { concept or design; and } \\
\text { analysis or } \\
\text { interpretation of data }\end{array}$ \\
& $\begin{array}{l}\text { Foundation Trust, Manchester } \\
\text { Centre, Manchester, United }\end{array}$ & \\
Kingdom & \\
\hline
\end{tabular}

\section{Appendix (continued)}

\begin{tabular}{|c|c|c|}
\hline Name & Location & Contribution \\
\hline $\begin{array}{l}\text { Ruth } \\
\text { Dobson, } \\
\text { MRCP, PhD }\end{array}$ & $\begin{array}{l}\text { Preventive Neurology Unit, } \\
\text { Wolfson Institute of Preventive } \\
\text { Medicine, Queen Mary } \\
\text { University of London, London, } \\
\text { United Kingdom; Department } \\
\text { of Neurology, Royal London } \\
\text { Hospital, Barts Health NHS } \\
\text { Trust, London, United } \\
\text { Kingdom }\end{array}$ & $\begin{array}{l}\text { Drafting/revision of the } \\
\text { manuscript for content, } \\
\text { including medical } \\
\text { writing for content; } \\
\text { study concept or design; } \\
\text { and analysis or } \\
\text { interpretation of data }\end{array}$ \\
\hline
\end{tabular}

\section{References}

1. Bosch X, Saiz A, Ramos-Casals M; BIOGEAS Study Group. Monoclonal antibody therapy-associated neurological disorders. Nat Rev Neurol. 2011;7:165-172.

2. TNF neutralization in MS: results of a randomized, placebo-controlled multicenter study. The Lenercept Multiple Sclerosis Study Group and The University of British Columbia MS/MRI Analysis Group. Neurology. 1999;53: 457-465.

3. Gregory AP, Dendrou CA, Attfield KE, et al. TNF receptor 1 genetic risk mirrors outcome of anti-TNF therapy in multiple sclerosis. Nature. 2012;488:508-511.

4. Morris Z, Whiteley WN, Longstreth WT Jr, et al. Incidental findings on brain magnetic resonance imaging: systematic review and meta-analysis. BMJ. 2009;339:b3016.

5. BSRBR-RA Study homepage. bsrbr.org. Accessed November 1, 2020.

6. Watson K, Symmons D, Griffiths I, Silman A. The British Society for Rheumatology biologics register. Ann Rheum Dis. 2005;64(suppl 4):iv42-3.

7. van der Heijde DM, van't Hof MA, van Riel PL, et al. Judging disease activity in clinical practice in rheumatoid arthritis: first step in the development of a disease activity score. Ann Rheum Dis. 1990;49:916-920.

8. Maska L, Anderson J, Michaud K. Measures of functional status and quality of life in rheumatoid arthritis: Health assessment Questionnaire Disability Index (HAQ), Modified Health Assessment Questionnaire (MHAQ), Multidimensional Health Assessment Questionnaire (MDHAQ), Health Assessment Questionnaire II (HAQII), Improved Health Assessment Questionnaire (Improved HAQ), and Rheumatoid Arthritis Quality of Life (RAQoL). Arthritis Care Res. 2011;63(suppl 11):S4-S13.

9. Brown EG, Wood L, Wood S. The medical dictionary for regulatory activities (MedDRA). Drug Saf. 1999;20:109-117.

10. Thompson AJ, Banwell BL, Barkhof F, et al. Diagnosis of multiple sclerosis: 2017 revisions of the McDonald criteria. Lancet Neurol. 2018;17:162-173.

11. Mackenzie IS, Morant SV, Bloomfield GA, MacDonald TM, O’Riordan J. Incidence and prevalence of multiple sclerosis in the UK 1990-2010: a descriptive study in the General Practice Research Database. J Neurol Neurosurg Psychiatry. 2014;85:76-84.

12. Kopp TI, Delcoigne B, Arkema EV, et al. Risk of neuroinflammatory events in arthritis patients treated with tumour necrosis factor alpha inhibitors: a collaborative population-based cohort study from Denmark and Sweden. Ann Rheum Dis. 2020; 79:566-572.

13. Kunchok A, Aksamit AJ Jr, Davis JM III, et al. Association between Tumor necrosis factor Inhibitor exposure and inflammatory central nervous System events. JAMA Neurol. 2020;77:937-946.

14. Pérez-De-Lis M, Retamozo S, Flores-Chávez A, et al. Autoimmune diseases induced by biological agents. A review of 12,731 cases (BIOGEAS Registry). Expert Opin Drug Saf. 2017;16:1255-1271.

15. Public Health England. Multiple Sclerosis: Prevalence, Incidence and Smoking Status_Data Briefing; 2020. gov.uk/government/publications/multiple-sclerosisprevalence-incidence-and-smoking-status/multiple-sclerosis-prevalence-incidenceand-smoking-status-data-briefing. Accessed November 1, 2020.

16. Butzkueven H, O’Brien TJ, Sedal L. Combined peripheral nerve and central nervous system demyelination in a patient with chronic inflammatory demyelinating polyneuropathy. J Clin Neurosci. 1999;6:358-360.

17. Degelman ML, Herman KM. Smoking and multiple sclerosis: a systematic review and meta-analysis using the Bradford Hill criteria for causation. Mult Scler Relat Disord. 2017; 17:207-216.

18. Dobson R, Giovannoni G. Autoimmune disease in people with multiple sclerosis and their relatives: a systematic review and meta-analysis. J Neurol. 2013;260:1272-1285. 


\title{
Neurology \\ Neuroimmunology \& Neuroinflammation
}

\author{
Demyelinating Events Following Initiation of Anti-TNF $\alpha$ Therapy in the British Society \\ for Rheumatology Biologics Registry in Rheumatoid Arthritis \\ Thomas R.P. Taylor, James Galloway, Rebecca Davies, et al. \\ Neurol Neuroimmunol Neuroinflamm 2021;8; \\ DOI 10.1212/NXI.0000000000000992
}

This information is current as of April 16, 2021

\begin{abstract}
Updated Information \&
Services

including high resolution figures, can be found at:

http://nn.neurology.org/content/8/3/e992.full.html

References

This article cites 16 articles, 5 of which you can access for free at: http://nn.neurology.org/content/8/3/e992.full.html\#\#ref-list-1

Citations

This article has been cited by 1 HighWire-hosted articles:

http://nn.neurology.org/content/8/3/e992.full.html\#\#otherarticles

Subspecialty Collections

This article, along with others on similar topics, appears in the following collection(s):

All Demyelinating disease (CNS)

http://nn.neurology.org//cgi/collection/all_demyelinating_disease_cns All Medical/Systemic disease

http://nn.neurology.org//cgi/collection/all_medical_systemic_disease Autoimmune diseases

http://nn.neurology.org//cgi/collection/autoimmune_diseases

Permissions \& Licensing

Information about reproducing this article in parts (figures,tables) or in its entirety can be found online at:

http://nn.neurology.org/misc/about.xhtml\#permissions

Reprints

Information about ordering reprints can be found online:

http://nn.neurology.org/misc/addir.xhtml\#reprintsus

Neurol Neuroimmunol Neuroinflamm is an official journal of the American Academy of Neurology.

Published since April 2014, it is an open-access, online-only, continuous publication journal. Copyright

Copyright (C) 2021 The Author(s). Published by Wolters Kluwer Health, Inc. on behalf of the American

Academy of Neurology.. All rights reserved. Online ISSN: 2332-7812.
\end{abstract}

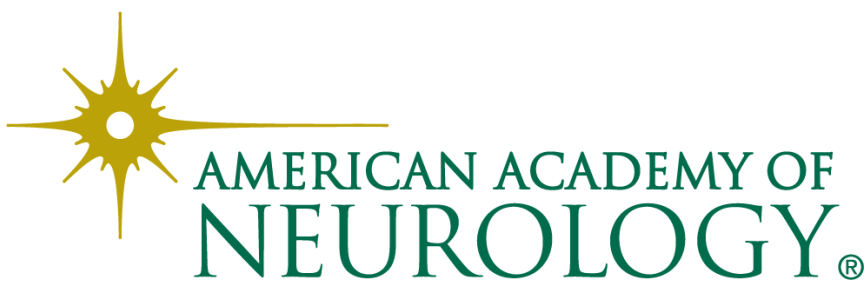

